\title{
Low-grade infections as a possible cause of arthrofibrosis after total knee arthroplasty
}

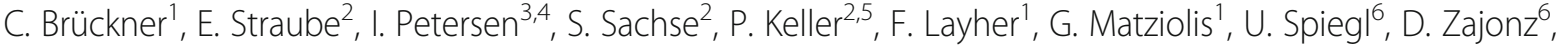 \\ M. Edel ${ }^{7}$ and A. Roth ${ }^{1,6,8^{*}}$
}

\begin{abstract}
Purpose: Arthrofibrosis after total knee arthroplasty represents a considerable burden for the patient and a therapeutic challenge for the practitioner. One possible cause discussed in the literature is a low-grade infection. This hypothesis should be examined within the scope of this retrospective study.

Patients and methods: Nineteen patients with clinical symptoms of arthrofibrosis after primary total knee arthroplasty were examined between January, 1999 and January, 2012. Incorrect positioning was radiologically ruled out. All patients were examined clinically (score of Freeman as well as Blauth and Jäger), radiologically (component and leg alignment, patella height according to Insall and Salvati), microbiologically (culture-based procedures), molecular biologically (PCR) and histologically in the course of an open revision of the prosthesis.

Results: According to the score of Freeman et al. (1977), a highly significant improvement in pain $(p=0.007)$ and in the overall score $(p=0.003)$ was shown. The knee joint mobility did not change significantly $(p=0.795)$. PCR was negative in 17 patients. One patient showed a PCR-positive result of the synovial membrane for Corynebacterium spp., while Staphylococcus warneri was detected in the culture. Another patient had a positive result of synovia PCR for Enterococcus cecorum as well as Corynebacterium spp. However, this culture was sterile. In 16 patient samples, no bacterial growth was detectable. Two samples were not evaluable. The main histopathological findings were synovialitis and fibrosis.

Conclusion: The hypothesis of low-grade-infection-induced arthrofibrosis after total knee arthroplasty could not be confirmed in this study. However, based on this small study population the conclusion needs to be confirmed by new and larger studies, ideally prospectively designed including a control group.
\end{abstract}

Keywords: Total knee arthroplasty, Arthrofibrosis, PCR

\section{Introduction}

The causes of postoperative pain after a total knee arthroplasty, which is accompanied by limited mobility, often remain unclear. The clinical pathology corresponds to stiff-knee or arthrofibrosis, although a precise definition of the disease is still lacking. Incorrect implant positioning and instabilities can be possible causes [1]. A hypothesis for the development of arthrofibrosis is a low-grade infection [2,3].

\footnotetext{
* Correspondence: Andreas.Roth@medizin.uni-leipzig.de

'Orthopaedic Professorship of the University Hospital Jena, Orthopaedic

Department of the Waldkliniken Eisenberg, Eisenberg, Germany

${ }^{6}$ Department of Orthopaedics, Traumatology and Plastic Surgery, University

Hospital Leipzig, Leipzig, Germany

Full list of author information is available at the end of the article
}

Arthrofibrosis is described as a progressive and fibrous process within a joint, often associated with inflammation $[4,5]$. Up to the present day, numerous hypotheses with the same fundamental idea exist, which is based on a hypoxia of the synovialis caused by a circulatory disorder [5]. This is thought to induce a distinctly increased synthesis of fibrotic material in the sense of "pathological wound healing" or "disturbed remodelling" [6]. At the beginning it is typically localized, but over time arthrofibrosis can spread throughout the entire joint. If the practitioner finds a cause for this condition, such as an incorrect implantation or an insufficient postoperative mobilization, a revision operation is conceivable. In most patients, however, it is difficult to accurately identify the pathogenesis that causes arthrofibrosis.

(c) The Author(s). 2019 Open Access This article is distributed under the terms of the Creative Commons Attribution 4.0 International License (http://creativecommons.org/licenses/by/4.0/), which permits unrestricted use, distribution, and 
A favoured hypothesis of the development of arthrofibrosis is infection. Joints treated with an implant are more susceptible to infections than joints without an implant [2,3]. While high-grade joint infections often exhibit a clear clinical and microbiological indication of inflammation, low-grade infections usually provide no distinct evidence. Thus, this kind of infection still presents a particular challenge to today's clinical practices and diagnostics.

This retrospective study examines the hypothesis of low-grade-infection-induced arthrofibrosis after primary total knee arthroplasty. In order to confirm this assumption, samples were taken from the synovia as well as synovial membrane during revision operation. Subsequently, the samples were examined for bacteria using conventional microbiological analytical methods (microscopy, pathogen culture) and 16S-rRNA-PCR as supplementary molecular genetic diagnostic procedure. Moreover, it should be determined whether the microbiological findings correlate with the histopathology of arthrofibrosis. If the hypothesis of low-grade infection as the source of arthrofibrosis is confirmed, it will optimize preoperative diagnosis and treatment for patients with this disorder.

\section{Material and methods}

The study was approved by the ethics committee of the Friedrich-Schiller-University Jena (No. 3409-03/12).

In consideration of previously defined inclusion and exclusion criteria (Table 1), 19 patients with clinically confirmed arthrofibrosis after primary total knee arthroplasty $(01 / 1999-01 / 2012)$ were re-examined within the scope of a revision operation (01/2010-01/2012). Intraoperatively samples of the synovia (one sample) and synovial membrane (three samples) were taken and examined to rule out an infection using conventional microbiological (microscopy, pathogen culture) and molecular biological methods (16S-rRNA-PCR). In cases without measurable DNA concentrations, a GAPDH-PCR was performed. To confirm the clinical suspicion of arthrofibrosis, three further samples of the synovial membrane were taken for the histopathological examination.

The anamnesis included location and time of primary total knee arthroplasty, retention time of the implant up to revision, invasive or surgical interventions prior to

Table 1 Inclusion-/exclusion criteria of the study

\begin{tabular}{ll}
\hline inclusion criteria & exclusion criteria \\
\hline - persistent painful limitation of motion & - high-grade-infection \\
after TKA & - incorrect implantation of \\
- high degree of psychological strain, & the TKA \\
restricted quality of life & - drug abuse \\
- informed consent concerning the & - temporary immobilization \\
study design & after the revision \\
\hline
\end{tabular}

and after total knee arthroplasty as well as secondary diseases.

Before revision surgery and three months after revision, the following clinical parameters were collected: effusion, swelling, hyperthermia, instabilities, retropatellar symptoms of discomfort and the range of motion (extension/flexion) according to the Neutral Zero method. During the same time interval, the clinical scores pursuant to Freeman et al. [7, 8] as well as Blauth and Jäger $[4,8]$ were evaluated. While pain intensity, ability to walk and range of motion (Table 2) are assessed by the score of Freeman et al., the classification of knee joint stiffness (Table 3) is evaluated using the score of Blauth and Jäger.

Radiologically, the valgus- and varus-angle were determined via an image of the entire lower extremity. The slope and the patella height according to Insall and Salvati [9] were specified in the lateral beam path.

In all patients, open revision and arthrolysis followed after a closed anaesthetic mobilisation via a medial parapatellar approach. An intraoperative single-shot antibiotic treatment was performed after sample extraction in all patients.

In addition to the descriptive data presentation [mean value $(\mathrm{MV})$, standard deviation $(\sigma)$, minimum (min), maximum (max)] the statistical evaluation (SPSS version 19) includes the analysis of the changes resulting from the revision. In this context, the mobility and clinical scores pursuant to Freeman et al. $[7,8]$ as well as Blauth

Table 2 Score of Freeman et al. [7]

\begin{tabular}{|c|c|c|}
\hline \multirow[t]{4}{*}{ Pain } & None & 50 "acceptable" \\
\hline & $\begin{array}{l}\text { Mild (an "occasional twinge", not a } \\
\text { spontaneous complaint, does not } \\
\text { require analgesia, does not limit } \\
\text { function) }\end{array}$ & 40 "acceptable" \\
\hline & $\begin{array}{l}\text { Moderate (may require analgesia but } \\
\text { does not limit function) }\end{array}$ & 15 \\
\hline & Severe (any other pain) & 0 \\
\hline \multirow{4}{*}{$\begin{array}{l}\text { Ability to } \\
\text { walk }\end{array}$} & Outdoors, 30 minutes or more & 20 "acceptable" \\
\hline & Outdoors, 0 - 30 minutes & 15 "acceptable" \\
\hline & Indoors & 5 \\
\hline & Unable & 0 \\
\hline \multirow{4}{*}{$\begin{array}{l}\text { Range of } \\
\text { motion }\end{array}$} & $80^{\circ}$ & 30 "acceptable" \\
\hline & $60^{\circ}-79^{\circ}$ & 20 \\
\hline & $30^{\circ}-59^{\circ}$ & 5 \\
\hline & $0^{\circ}-29^{\circ}$ & 0 \\
\hline \multicolumn{2}{|c|}{ If "acceptable" in all three categories add: } & 10 \\
\hline \multirow{4}{*}{$\begin{array}{l}\text { Acceptable } \\
\text { Result: }\end{array}$} & Overall assessment & $95-110$ points \\
\hline & Pain & 40 - 50 points \\
\hline & Function & $15-20$ points \\
\hline & Movement & 30 points \\
\hline
\end{tabular}


Table 3 Score of Blauth and Jäger [4]

\begin{tabular}{ll}
\hline grade I & Range of motion at least $90^{\circ}$ \\
grade II & Range of motion $60^{\circ}-90^{\circ}$ \\
grade III & Range of motion $30^{\circ}-60^{\circ}$ \\
grade IV & Range of motion at least range $30^{\circ}$ \\
\hline
\end{tabular}

and Jäger $[4,8]$ are evaluated by means of the Wilcoxon test. A cross-table and the chi-square test according to Pearson were used to check the frequency distribution of the score of Blauth and Jäger $[4,8]$. The significance level of all statistical tests was set to $p \leq 0.05$.

\section{Results}

Nineteen patients (11 men, 8 women) with an average age of 66.37 years $(\sigma=8.34$ years) were included in the study. All patients suffered from relevant knee pain at and limited range of movement after initial total knee arthroplasty. With reference to the previously defined exclusion criteria, two patients were excluded from the clinical follow-up and the score collection. Overall, 11 left and eight right knee joints were affected. Thirteen of these patients received a total knee endoprosthesis in-house and six patients externally. In 12 patients, at least one arthroscopic procedure was performed prior to primary endoprosthesis implantation. The average time interval between primary implant surgery and revision was 3.39 years $(\sigma=2.76$ years $)$. An arthrotomy was performed in nine patients during this period (Fig. 1).

Five patients showed obesity as a secondary disease. Additionally, it was proven that two of them were affected by hyperuricemia and one by solitary hyperuricemia. Two more patients suffered from neurological diseases (1x Parkinson's disease, $1 \mathrm{x}$ infantile cerebral palsy with diplegia and spasticity).

The evaluation of the clinical examination parameters prior to revision surgery (19 patients) revealed as cardinal symptoms peripatellar pain symptoms, instability and swelling followed by effusion and hyperthermia. After revision surgery (17 patients) effusion, swelling, and peripatellar pain represented the main symptoms (Fig. 2).

All patients had a preoperative limitation of mobility related to flexion, extension or both. Neither flexion, nor the extension deficit and overall range of motion showed any significant improvement three months after revision (Table 4). With regard to the score of Freeman et al. [7, 8] there was a highly significant reduction of pain $(p=0.007)$ and an improvement in the overall score $(p=0.003)$. Walking ability (ATW) $(p=0.458)$ and mobility of the knee joint (ROM) $(p=0.157)$ were not significantly altered (Fig. 3). According to the score of Blauth and Jäger $[4,8]$ no significant changes of the stiffness of the affected knee could be detected ( $p=0.708$ ) (Fig. 4).

The radiological examination showed an average tibiofemoral alignment of $6.7^{\circ}\left(\sigma=3.2^{\circ}\right)$, whereas the tibial slope averaged $7.2^{\circ}\left(\sigma=4.1^{\circ}\right)$. Concerning the score of Insall and Salvati [9], eight patients had a normally positioned patella $(\mathrm{LT} / \mathrm{LP}=1.03)$, eight patients a patella alta $(\mathrm{LT} / \mathrm{LP}>1.15)$ and three patients a patella baja $(\mathrm{LT} / \mathrm{LP}<$ 0.75) (normal range 0.8-1.04).

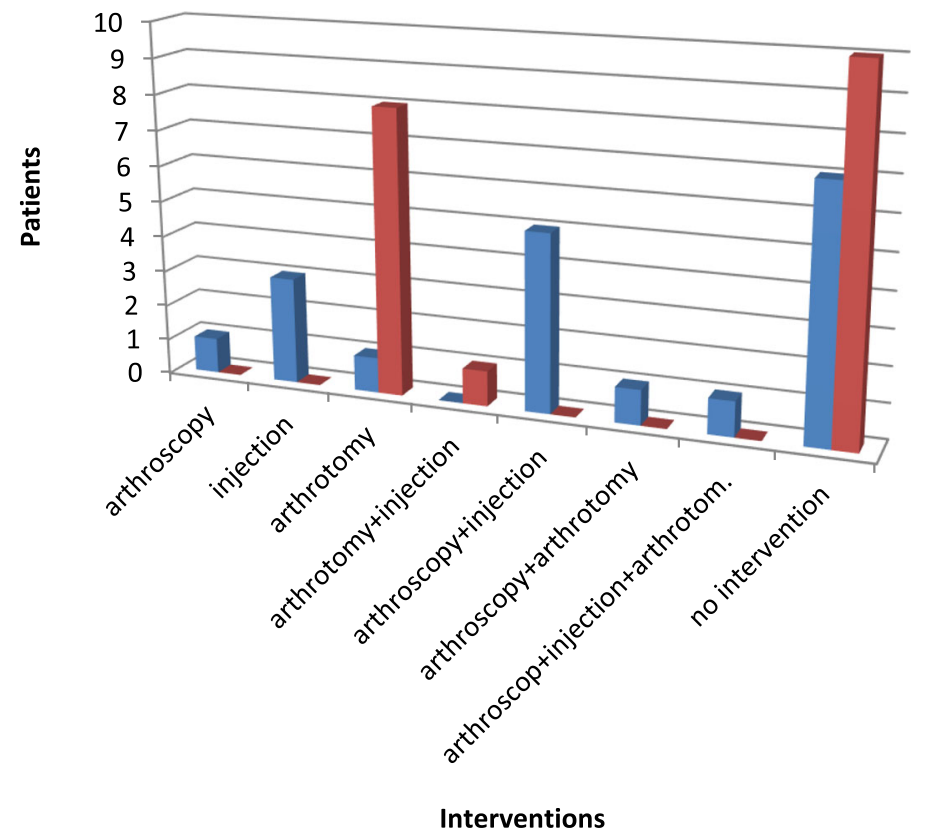

before TKA

after TKA

Fig. 1 invasive interventions before/after total knee arthroplasty 


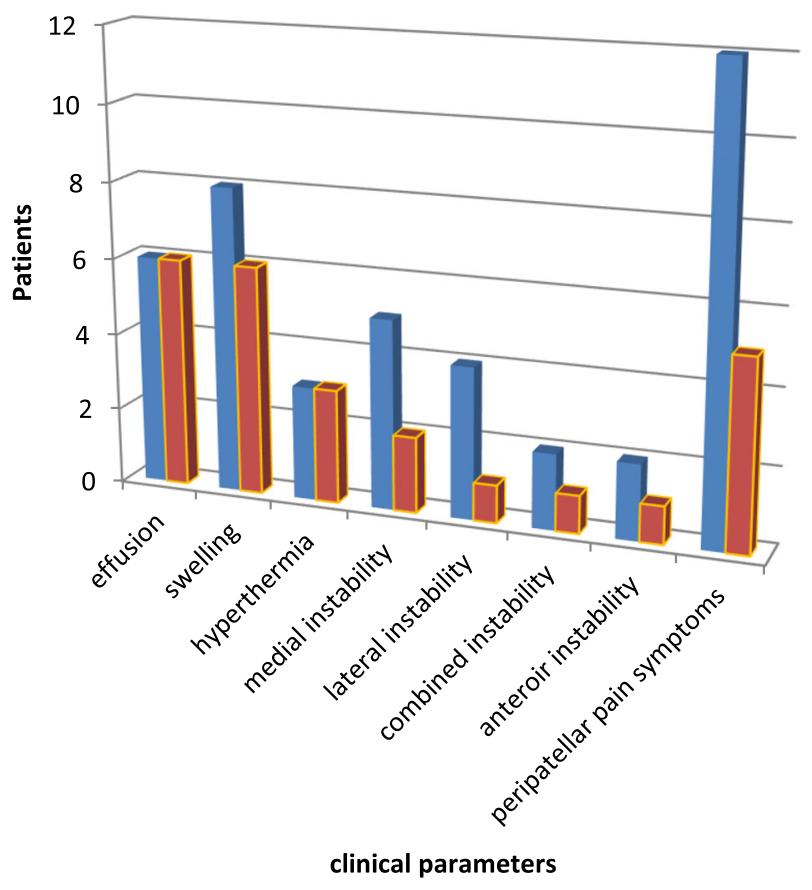

before revision

- 3 months after revision

Fig. 2 clinical parameters before/after revision

In addition to closed manipulation and open arthrolysis, the most frequent interventions were synovectomy $(n=11)$, followed by exchange of the inlay $(n=6)$, and peripatellar denervation $(n=4)$ (Fig. 5). Furthermore, a spacer was implanted in one patient with a positive culture, followed by a reimplantation as a two stage procedure. In three cases a complete replacement of the prosthesis was performed due to pronounced ligamentous instability.

PCR was negative in 17 patients. One patient showed a PCR-positive result of Corynebacterium spp. at the synovial membrane. Additionally, Staphylococcus warneri was found in the culture. Another patient had a positive result of synovia PCR for Enterococcus cecorum as well as Corynebacterium spp. However, all cultures of this patient remained sterile. No bacterial growth was

Table 4 Flexion/extension deficit and ROM before/after revision

\begin{tabular}{lllll}
\hline & Minimum & Maximum & $\begin{array}{l}\text { Mean } \\
\text { value }\end{array}$ & $\begin{array}{l}\text { Standard } \\
\text { deviation }\end{array}$ \\
\hline Flexion before revision & $40^{\circ}$ & $130^{\circ}$ & $91.76^{\circ}$ & $20.38^{\circ}$ \\
$\begin{array}{l}\text { Flexion after revision } \\
65^{\circ}\end{array}$ & $125^{\circ}$ & $92.06^{\circ}$ & $13.70^{\circ}$ \\
$\begin{array}{l}\text { Extension deficit before } \\
\text { revision }\end{array}$ & $0^{\circ}$ & $20^{\circ}$ & $2.65^{\circ}$ & $5.04^{\circ}$ \\
$\begin{array}{l}\text { Extension deficit after } \\
\text { revision }\end{array}$ & $-5^{\circ}$ & $10^{\circ}$ & $1.76^{\circ}$ & $3.93^{\circ}$ \\
$\begin{array}{l}\text { Range of motion } \\
\text { before revision }\end{array}$ & $35^{\circ}$ & $130^{\circ}$ & $89.12^{\circ}$ & $22.52^{\circ}$ \\
$\begin{array}{l}\text { Range of motion after } \\
\text { revision }\end{array}$ & $55^{\circ}$ & $125^{\circ}$ & $90.29^{\circ}$ & $15.26^{\circ}$ \\
\hline
\end{tabular}

detectable in all further samples (16 patients). Two samples could not been evaluated (Table 5).

The preoperative laboratory values showed no significant increase (CRP: mean $9.20 \mathrm{mg} / \mathrm{l}$, min. 0.3, max. 44.9; leucocytes: mean $10.6 \mathrm{Gpt} / \mathrm{l}$, min. 4.6, $\max$. 10.6). For the patients tested positive in the PCR, they were for CRP at 15.7 resp. $1.5 \mathrm{mmol} / \mathrm{l}$ and for the leucocytes at $9.7 \mathrm{resp} .4 .8 \mathrm{Gpt} / \mathrm{l}$.

The main histopathological results were synovialitis, fibrosis and synovialitis with fibrosis. All the other histologies exhibited at least one of the latter two characteristics. In five cases, the term "arthrofibrosis" was used in the finding (Fig. 6). Moreover, no granulocytic elements indicating a low-grade infection were found.

\section{Discussion}

Arthrofibrosis is usually an inflammatory, progressive fibrous process. After total knee arthroplasty, it occurs with a probability of up to $10 \%[5,10-12]$. In our patients collective, it was conspicuous that arthroscopy had been performed in 12 out of 19 patients (63.2\%) before primary knee arthroplasty. Particularly arthroscopy represents a significant risk factor for the development of arthrofibrosis [13, 14]. In the investigated patient collective, secondary diseases favouring arthrofibrosis $[1,15]$ were found in the form of obesity (26.3\%), obesity with hyperuricemia (10.5\%), hyperuricemia (5.3\%) and pre-existing neurological diseases (10.5\%). However, no significant accumulation of secondary diseases could be detected. 


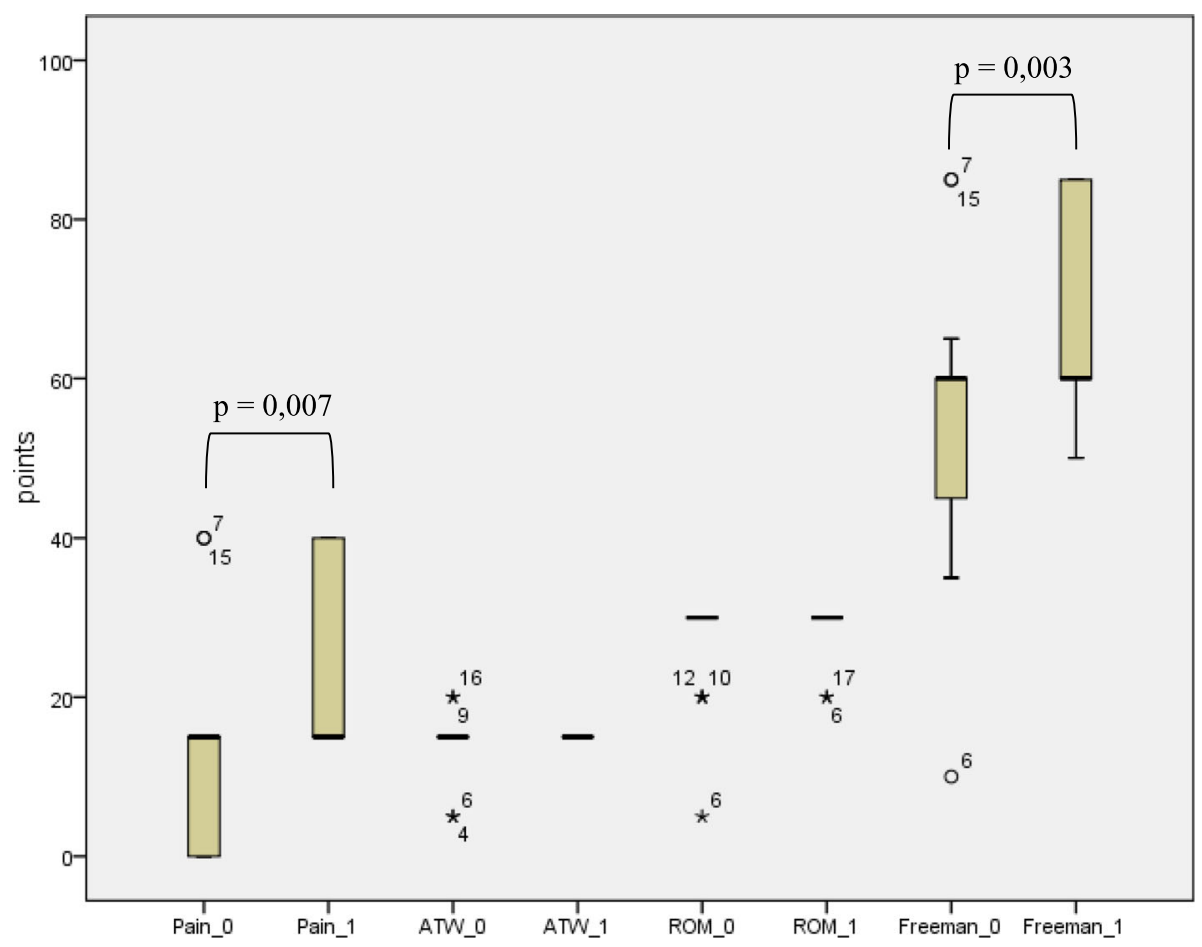

Fig. 3 score of Freeman et al. [7] before/after revision

In addition to instability, effusion, swelling and hyperthermia, peripatellar pain was the main clinical symptom [16-18]. Prior surgery, 63\% of our patients complained of retropatellar pain, whereas this percentage dropped to $29 \%$ after revision surgery. One reason for this is the high contact pressure of the patella against the femoral component [19]. Unfortunately, no significant improvement in the range of motion could be achieved through revision surgery. However, a significant and relevant reduction in pain was visible. The authors consider this as the most important benefit in patients with sufficient knee function for daily living.

Radiologically, incorrect endoprosthesis positioning could be ruled out. Moreover, our results show that patella alta (eight patients) occurred more frequently than a patella baja, which is a strong risk factor for the development of peripatellar pain symptoms after total knee arthroplasty $[18,20]$.

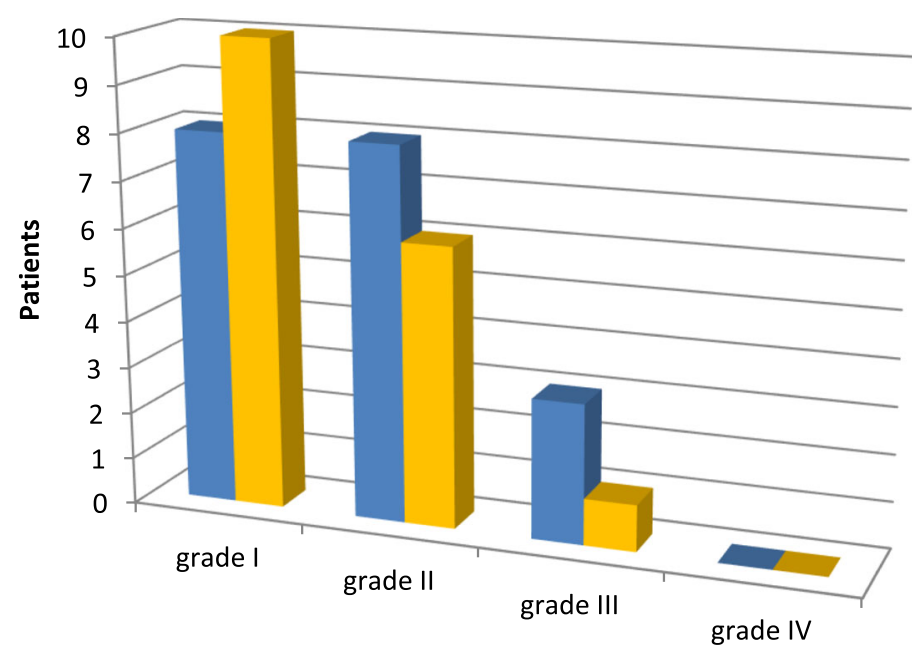

before revision

after revision

Fig. 4 score of Blauth and Jäger [4] 


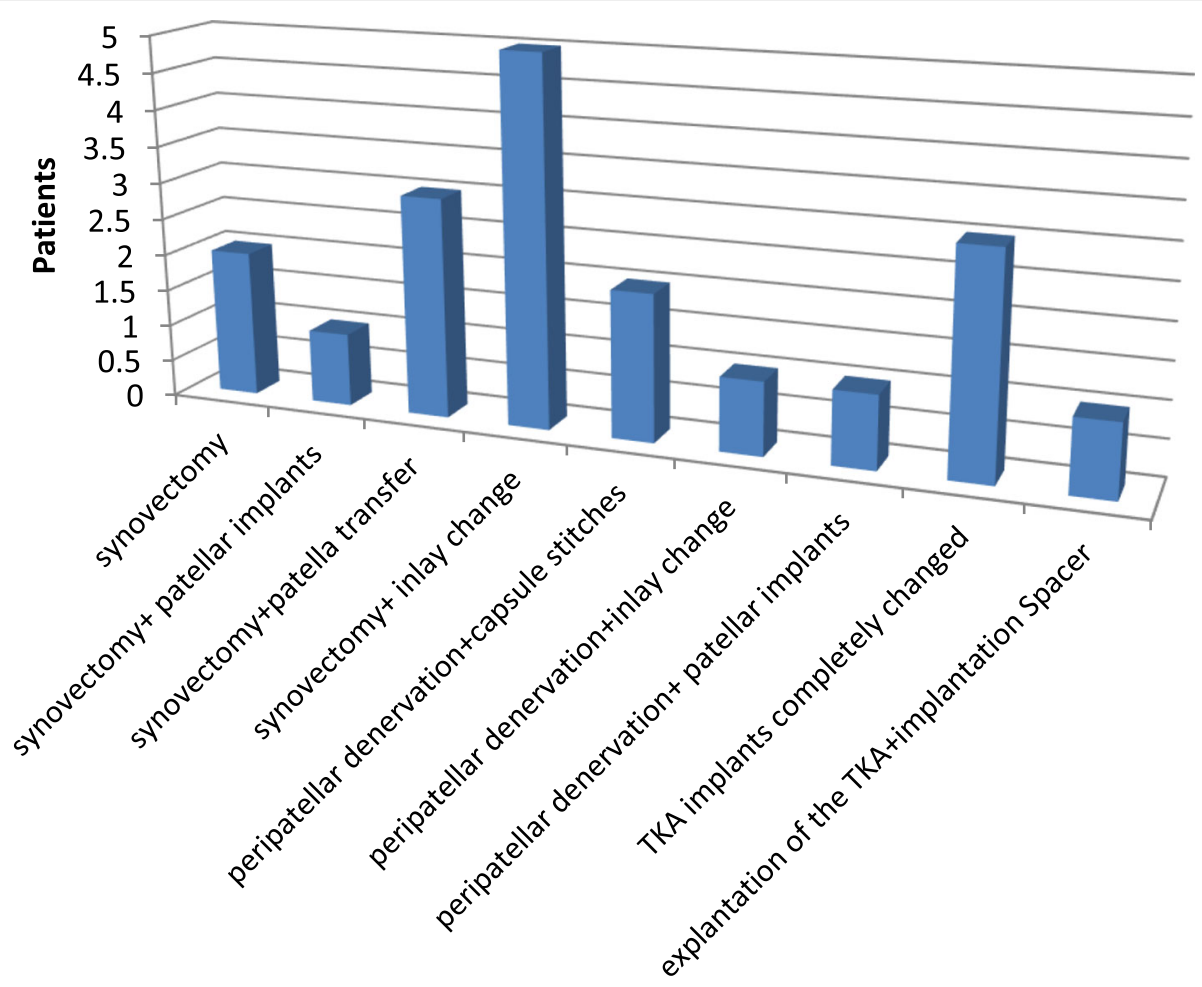

Fig. 5 additional operative interventions during revision

In part, arthroscopy is recommended as a first-line therapy $[21,22]$. However, the period between primary implantation and revision surgery should be between three and six months, maximum one year [23]. In these 19 patients, this period was up to three years and therefore arthrotomy was consistently chosen [24-26].

The inflammatory parameters (CRP and leucocytes) did not help us to diagnose an active periprosthetic infection, particular in patients with intraarticular bacterial detection. In the PCR of the synovial membrane of one patient gram-positive bacterium Corynebacterium spp., typical bacteria of the skin, was found [27]. Its culture delivered Staphylococcus warneri, conspicuous for joint infections [28, 29]. The synovia PCR of a second patient was positive for Enterococcus cecorum and Corynebacterium spp., which are again part of the normal skin and mucous membrane flora
[27]. However, the culture of this patient was negative.

Divergent results between culture and PCR can be explained by the limited sensitivity of PCR to different pathogen concentrations of individual bacteria. Furthermore, this could also be caused by an unknown outpatient antibiotic treatment. In addition, a migration of pathogen DNA by macrophages and granulocytes via the bloodstream is possible [30-36]. Moreover, false-positive results in the culture due to contamination, e.g. during sampling, transport and processing in the laboratory, cannot be completely ruled out $[37,38]$.

The classic microbiological methods (microscopy and pathogen culture) can remain false-negative in spite of an existing infection due to insufficient bacterium load, the presence of a highly variable pathogen species with delayed growth cycles or due to an antibiotic therapy. Especially in the case of "difficult-to-treat" bacteria like

Table 5 Microbiological and molecular biological results

\begin{tabular}{lllll}
\hline Patients & Culture Synovia & Culture Synovial Membrane & PCR Synovia & PCR Synovial Membrane \\
\hline 15 & sterile & sterile & negative & negative \\
1 & sterile & sterile & positive & negative \\
& & & Enterococcus cecorum & \\
1 & positive & Corynebacterium spp. & positive \\
& Staphylococcus warneri & sterile & negative & Corynebacterium spp. \\
2 & not evaluable & not evaluable & negative & negative \\
\hline
\end{tabular}




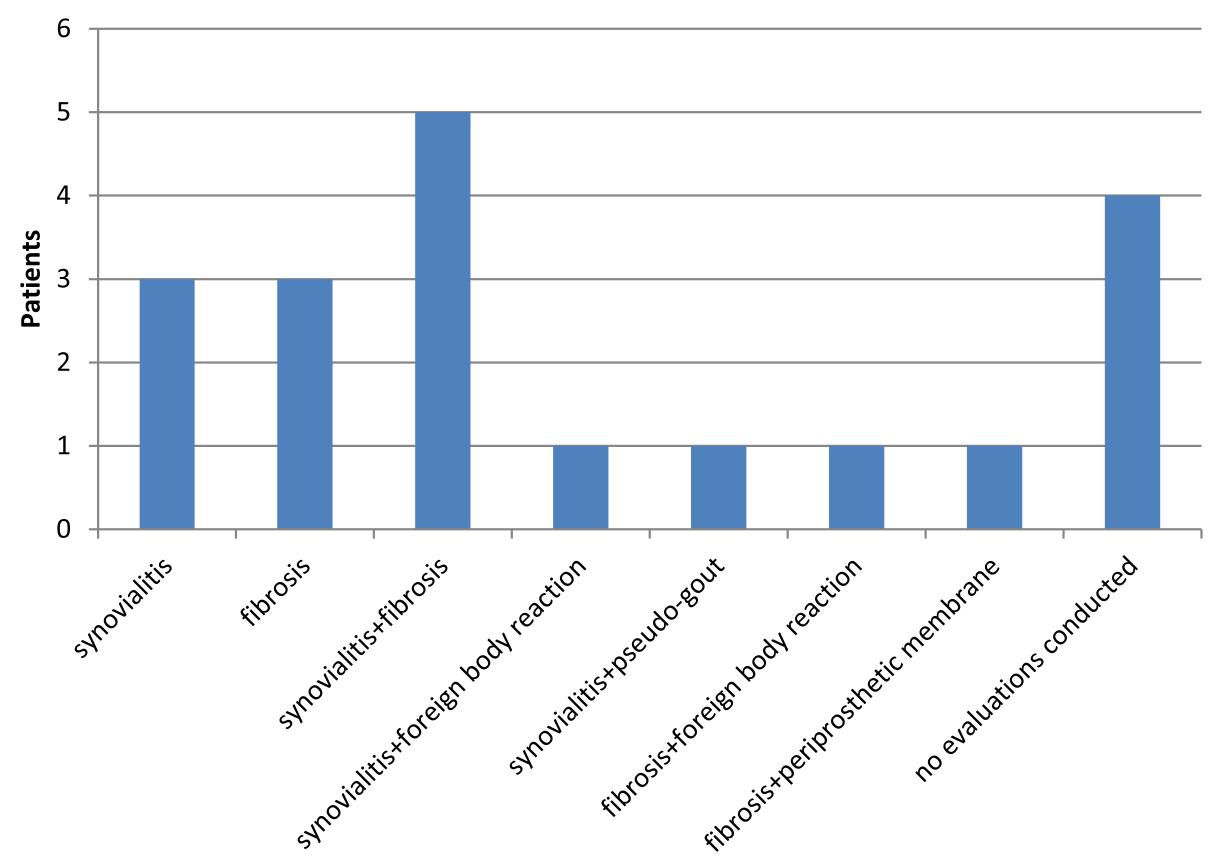

Fig. 6 histopathological results

"small colony variants" (SCV), it is sometimes necessary to cultivate them over a long period of time $[15,39]$. Moreover, it can be difficult to unmask the individual pathogens in a mixed polymicrobial flora [15]. Therefore, multiple inspections of the samples appear to be useful [40].

Morgenstern et al. were able to demonstrate that the results of PCR were essentially comparable to those of the culture in the diagnosis of periprosthetic infections [41]. Here, PCR was more suitable for the detection of low virulence bacteria such as Cutibacterium spp. and coagulase-negative Staphylococci. However, it shows the fundamental suitability of both methods. In the case of negative cultures, the performance of a PCR can be appropriate and expedient in a justified individual case, despite the additional time and cost [31].

The histopathological examination results of our study depicted inflammatory processes in the form of synovialitis and fibrosis. However, there were no granulocytic elements indicating a low-grade infection. Abdul et al. histologically described a dramatic tissue remodelling, increased collagen deposition and increased (myo)fibroblast staining in tissue from revision total knee arthroplasty [54]. Therefore, conventional histologies are not sufficient to define histopathological changes as an "arthrofibrosis".

The present study has some limitations. First of all, its retrospective design has to be mentioned. The number of patients included was low, which leads to an unpowered study and risk of type II statistical error. Minor criteria for periprosthetic infections were not known at the time of taking the samples and therefore were not considered in the present study [55]. Furthermore, it would have been desirable to integrate a control group without arthrofibrosis into the study in order to draw comparisons and conclusions. Several approaches of the same samples are perspectively recommended for PCR. Moreover, a follow-up study with a higher number of cases, which may be multi-sited, could contribute to a verification of the results.

Arthrofibrosis is a progressive process of joint fibrosis accompanied by inflammatory reactions. There was a universal definition and consensus in international panels of experts in 2016 [42]. These authors defined a post-operative fibrosis as the limited range of movement in flexion and/or extension, that is not attributable to an osseous or prosthetic block to movement from malaligned, malpositioned or incorrectly sized components, metal hardware, ligament reconstruction, infection (septic arthritis), pain, chronic regional pain syndrome (CRPS) or other specific causes, but due to soft-tissue fibrosis that was not present pre-operatively. From the authors' point of view, pain represents one of the most essential symptoms. The cause of arthrofibrosis after total knee endoprosthesis is multifactorial [43-53].

If the hypothesis of a low-grade-infection-induced arthrofibrosis had been supported, a decisive optimization of the pre-operative diagnosis and subsequent therapy would perspectively have been possible. However, our study of 19 patients showed that a low-grade infection 
was not the cause of arthrofibrosis. For this reason, the hypothesis must be rejected. However, based on the limited patients included over a time period of three years, which extrapolates to five or six patients a year prospectively designed studies such as multi-sited studies including a control group are warranted to support this conclusion.

\section{Conclusion}

The hypothesis of low-grade-infection-induced arthrofibrosis after total knee arthroplasty could not be confirmed in this study.

\section{Abbreviations}

ATW: Ability to walk; CRP: C-reactive protein; CRPS: Chronic regional pain syndrome; DNA: Deoxyribonucleic acid; GAPDH: Glyceraldehyde 3-phosphate dehydrogenase; LP: Length of the patella/largest diagonal diameter of the patella; LT: Length of the patella tendon; MV: Mean value; PCR: Polymerase chain reaction; ROM: Range of motion; rRNA: Ribosomal ribonucleic acid; SCV: Small colony variants

\section{Acknowledgments}

We acknowledge support from the German Research Foundation (DFG) and Leipzig University within the program of Open Access Publishing.

\section{Consent of publication}

All patients of our study gave their written informed consent for participation and publication of their anonymized data.

\section{Funding}

This study was carried out without funding. We received support from the German Research Foundation (DFG) and Leipzig University within the program of Open Access Publishing.

\section{Availability of data and materials}

The datasets used and/or analysed during the current study are available from the corresponding author upon reasonable request.

\section{Authors' contributions}

AR initiated the work and is the head of the expert team. CB has carried out the data collection and presentation. She also has contributed significantly to the preparation of the manuscript. DZ was part of the expert team and a major contributor in writing the manuscript. ME translated the article. US revised the manuscript again and corrected the English. FL and GM gave statistical support, endorsed the drafting of the article and revised it critically. ES and IP helped with data collection. AR and CB were mainly responsible for patient treatment as well as being members of the expert group. SS, ES and PK were responsible for microbiological examination, while IP performed the histological examination. All authors read and approved the final manuscript.

\section{Ethics approval and consent to participate}

The ethics committee of the University Hospital Jena in Germany granted ethical approval (ref. no. 3409-03/12). The committee is listed in the Institutional Review Board (IRB) of the Office for Human Research Protections (OHRP) IORG0003487, IRB00004153.

\section{Competing interests}

All authors declare no competing interests.

\section{Publisher's Note}

Springer Nature remains neutral with regard to jurisdictional claims in published maps and institutional affiliations.

\section{Author details}

'Orthopaedic Professorship of the University Hospital Jena, Orthopaedic Department of the Waldkliniken Eisenberg, Eisenberg, Germany. ${ }^{2}$ Institute of Medical Microbiology, Friedrich-Schiller-University Jena, Jena, Germany.
${ }^{3}$ Institute of Pathology, Friedrich-Schiller-University Jena, Jena, Germany ${ }^{4}$ Institute of Pathology, SRH Waldklinikum Gera, Gera, Germany. Institute of Medical Microbiology, University of Zurich, Zurich, Switzerland. ${ }^{6}$ Department of Orthopaedics, Traumatology and Plastic Surgery, University Hospital Leipzig, Leipzig, Germany. ${ }^{7}$ ZESBO - Center for research on musculoskeletal systems, Leipzig, Germany. ${ }^{8}$ Klinik und Poliklinik für Orthopädie, Unfallchirurgie und Plastische Chirurgie, Bereich Endoprothetik/Orthopädie, Universitätsklinikum Leipzig AöR, Liebigstraße 20, 04103 Leipzig, Germany.

Received: 7 September 2018 Accepted: 11 December 2018

Published online: 10 January 2019

\section{References}

1. Heesterbeek PJ, Goosen JH, Schimmel JJ, et al. Moderate clinical improvement after revision arthroplasty of the severely stiff knee. Knee Surg Sports Traumatol Arthrosc. 2016;24:3235-41.

2. Uçkay I, Lübbeke A, Emonet S, et al. Low incidence of haematogenous seeding to total hip and knee prostheses in patients with remote infections. J Inf Secur. 2009:59:337-45.

3. Sendi P, Zimmerli W. Challenges in periprosthetic knee-joint infection. Int J Artif Organs. 2011;34:947-56.

4. Blauth W, Jaeger T. Arthrolysis of the knee joint. Orthopade. 1990;19:388-99.

5. Gollwitzer H, Burgkart R, Diehl P, et al. Therapy of arthrofibrosis after total knee arthroplasty. Orthopade. 2006;35:143-52.

6. Zeichen J, Haeder L, Jagodzinski M, et al. Lokalisation von TGF-beta und PDGF und deren Bedeutung für die Pathogenese der Arthrofibrose. Unfallchirurg. 2008;111(2):79-84.

7. Freeman MA, Sculco T, Todd RC. Replacement of the severely damaged arthritic knee by the ICLH (Freeman-Swanson) arthroplasty. J Bone Joint Surg Br. 1977;59:64-71.

8. Krämer KL, Maichl FP. 1993. Scores, Bewertungsschemata und Klassifikationen in der Orthopädie und Traumatologie. Stuttgart, New York: Georg Thieme Verlag.

9. Insall J, Salvati E. Patella position in the normal knee joint. Radiology. 1971; 101:101-4.

10. Daluga D, Lombardi AV Jr, Mallory TH, et al. Knee manipulation following total knee arthroplasty. Analysis of prognostic variables. J Arthroplast. 1991;6: $119-28$.

11. Maloney WJ. The stiff total knee arthroplasty: evaluation and management. J Arthroplast. 2002;17(4 Suppl 1):71-3.

12. Steffen R, von Bremen-Kühne R, Eppe T. Complications after total knee arthroplasty. Zentralbl Chir. 2003;128:74-7.

13. Newman ET, Herschmiller TA, Attarian DE, et al. Risk factors, outcomes, and timing of manipulation under anesthesia after total knee arthroplasty. J Arthroplasty. 2018;33:245-9.

14. Bong MR, Di Cesare PE. Stiffness after total knee arthroplasty. J Am Acad Orthop Surg. 2004;12:164-71.

15. Harrasser N, Lenze U, Pohlig F. Die periprothetische Gelenkinfektion: Diagnostik und Therapie. OUP. 2012;1:16-22.

16. Munzinger UK, Petrich J, Boldt JG. Patella resurfacing in total knee arthroplasty using metal-backed rotating bearing components: a 2- to 10year follow-up evaluation. Knee Surg Sports Traumatol Arthrosc. 2001; 9(Suppl 1):S34-42.

17. Riedt S. Das Femoropatellare Schmerzsyndrom nach Knietotalendoprothesen - dieMöglichkeit der Beeinflussung durch retropatellare Denervation. [Dissertation]. Tübingen: Eberhard Karls Universität; 2005.

18. Michalik R, Rath B, Springorum HR, et al. Anterior knee pain after total knee arthroplasty: Causes, diagnosis and treatment. Orthopade. 2016;45:386-98.

19. Tanikawa H, Tada M, Harato K, et al. Influence of Total Knee Arthroplasty on Patellar Kinematics and Patellofemoral Pressure. J Arthroplast. 2017;32:280-5.

20. Chonko DJ, Lombardi AV Jr, Berend KR. Patella baja and total knee arthroplasty (TKA): etiology, diagnosis, and management. SurgTechnol Int. 2004;12:231-8.

21. Hutchinson JR, Parish EN, Cross MJ. Results of open arthrolysis for the treatment of stiffness after total knee replacement. J Bone Joint Surg Br. 2005;87:1357-60.

22. Arbuthnot JE, Brink RB. Arthroscopic arthrolysis for the treatment of stiffness after total knee replacement gives moderate improvements in range of motion and functional knee scores. Knee Surg Sports Traumatol Arthrosc. 2010;18:346-51. 
23. Fitzsimmons SE, Vazquez EA, Bronson MJ. How to treat the stiff total knee arthroplasty?: a systematic review. Clin Orthop Relat Res. 2010;468:1096-106.

24. Lobenhoffer P, Tausendfreund J, Zeichen J, et al. Operative Therapie der Arthrofibrose. Arthroskopie. 1999;12:252-9.

25. Bosch U. Arthrofibrosis. Orthopäde. 2002;31:785-90.

26. Glinz W. Arthrofibrose. Arthroskopie. 1999;12:213.

27. Cazanave C, Greenwood-Quaintance KE, Hanssen AD, et al. Corynebacterium prosthetic joint infection. J Clin Microbiol. 2012:50:1518-23.

28. Campoccia D, Montanaro L, Visai L, et al. Characterization of 26 Staphylococcus warneri isolates from orthopedic infections. Int J Artif Organs. 2010;33:575-81.

29. Announ N, Mattei JP, Jaoua S, et al. Multifocal discitis caused by Staphylococcus warneri. Joint Bone Spine. 2004;71:240-2.

30. Janeway CA, Travers $P$, Walport M, et al. Immunologie. 5. Auflage. Heidelberg 2002, Berlin: Spektrum Akademischer Verlag.

31. Baiyee $\mathrm{EE}$, Flohe $\mathrm{S}$, Lendemans $\mathrm{S}$, et al. Expression and function of Toll-like receptor 9 in severely injured patients prone to sepsis. Clin Exp Immunol. 2006;145:456-62.

32. Gorlino CV, Ranocchia RP, Harman MF, et al. Neutrophils exhibit differential requirements for homing molecules in their lymphatic and blood trafficking into draining lymph nodes. J Immunol. 2014;193:1966-74.

33. Isogai S, Miyata S, Taha R, et al. CD4+ T cells migrate from airway to bone marrow after antigen inhalation in rats. J Allergy Clin Immunol. 2004;113: 455-61.

34. Zhang Q, Raoof $\mathrm{M}$, Chen $\mathrm{Y}$, et al. Circulating mitochondrial DAMPs cause inflammatory responses to injury. Nature. 2010;464:104-7.

35. Sparwasser T, Miethke T, Lipford G, et al. Bacterial DNA causes septic shock. Nature. 1997;386:336-7.

36. Sparwasser T, Vabulas RM, Villmow B, et al. Bacterial CpG-DNA activates dendritic cells in vivo: T helper cell-independent cytotoxic T cell responses to soluble proteins. Eur J Immunol. 2000;30:3591-7.

37. Fenollar F, Roux V, Stein A, et al. Analysis of 525 samples to determine the usefulness of PCR amplification and sequencing of the $16 \mathrm{~S}$ rRNA gene for diagnosis of bone and joint infections. J Clin Microbiol. 2006:44:1018-28.

38. Sontakke S, Cadenas MB, Maggi RG, et al. Use of broad range16S rDNA PCR in clinical microbiology. J Microbiol Methods. 2009;76:217-25.

39. Sendi P, Frei R, Maurer TB, et al. Escherichia coli variants in periprosthetic joint infection: diagnostic challenges with sessile bacteria and sonication. J Clin Microbiol. 2010:48:1720-5.

40. Cursons RT, Jeyerajah E, Sleigh JW. The use of polymerase chain reaction to detect septicemia in critically ill patients. Crit Care Med. 1999;27:937-40.

41. Morgenstern C, Cabric S, Perka C, et al. Synovial fluid multiplex PCR is superior to culture for detection of low-virulent pathogens causing periprosthetic joint infection. Diagn Microbiol Infect Dis. 2018:90:115-9.

42. Kalson NS, Borthwick LA, Mann DA, et al. International consensus on the definition and classification of fibrosis of the knee joint. Bone Joint J. 2016; 98-B:1479-88

43. Cheuy VA, Foran JRH, Paxton RJ, et al. Arthrofibrosis associated with Total knee arthroplasty. J Arthroplast. 2017;32:2604-11.

44. Freeman TA, Parvizi J, Della Valle CJ, et al. Reactive oxygen and nitrogen species induce protein and DNA modifications driving arthrofibrosis following total knee arthroplasty. Fibrogenesis Tissue Repair. 2009;2:5.

45. Freeman TA, Parvizi J, Dela Valle CJ, et al. Mast cells and hypoxia drive tissue metaplasia and heterotopic ossification in idiopathic arthrofibrosis after total knee arthroplasty. Fibrogenesis Tissue Repair. 2010;3:17

46. Hold GL, Untiveros P, Saunders KA, et al. Role of host genetics in fibrosis. Fibrogenesis Tissue Repair. 2009;2:6

47. Watson RS, Gouze E, Levings PP, et al. Gene delivery of TGF- $\beta 1$ induces arthrofibrosis and chondrometaplasia of synovium in vivo. Lab Investig. 2010;90: 1615-27.

48. Remst DF, Blaney Davidson EN, et al. Osteoarthritis-related fibrosis is associated with both elevated pyridinoline cross-link formation and lysyl hydroxylase 2b expression. Osteoarthr Cartil. 2013;21:157-64.

49. Pfitzner $T$, Röhner $E$, Krenn $V$, et al. BMP-2 dependent increase of soft tissue density in Arthrofibrotic TKA. Open Orthop J. 2012;6:199-203.

50. Bosch U, Zeichen J, Lobenhoffer $P$, et al. Arthrofibrosis: a chronic inflammatory process? Arthroskopie. 1999;12:117-20.
51. Paulos LE, Rosenberg TD, Drawbert J, et al. Infrapatellar contracture syndrome. An unrecognized cause of knee stiffness with patella entrapment and patella infera. Am J Sports Med. 1987;15:331-41.

52. Spague NF. O'Connor RL, fox JM. Arthroscopic treatment of posteroperative knee fibroarthrosis. Clin Orthop. 1982;166:165-72.

53. Murakami S, Muneta T, Furuya K, et al. Immunhistologic analysis of synovium in infrapatellar fat pad after anterior cruciate ligament injury. Am J Sports Med. 1995;23:763-8.

54. Abdul N, Dixon D, Walker A, Horabin J, et al. Fibrosis is a common outcome following total knee arthroplasty. Sci Rep. 2015;5:16469.

55. Zmistowski B, Della Valle C, Bauer TW, et al. Diagnosis of periprosthetic joint infection. J Orthop Res. 2014;32(Suppl 1):S98-107.
Ready to submit your research? Choose BMC and benefit from:

- fast, convenient online submission

- thorough peer review by experienced researchers in your field

- rapid publication on acceptance

- support for research data, including large and complex data types

- gold Open Access which fosters wider collaboration and increased citations

- maximum visibility for your research: over $100 \mathrm{M}$ website views per year

At BMC, research is always in progress.

Learn more biomedcentral.com/submissions 